\title{
Synthesis of Hydrophobic and Hydrophilic Loaded Mesoporous Silica Nanoparticles for Controlled Co- Delivery of Drugs
}

PRIYADHARSINI K

Tagore Engineering College

ANBUCHEZHIYAN M ( $\square$ chezhiyan70@gmail.com )

Valliammai Engineering College https://orcid.org/0000-0002-4481-0668

SANGEETHA K

DKM college for Women, vellore

SENGUTTUVAN N

Tagore Engineering College

RAJENDRAN SRIBALAN

Biochemie Innovations lab

\section{Research Article}

Keywords: Mesoporous silica, curcumin, doxorubicin, gating, co-delivery, biocompatible

Posted Date: April 5th, 2021

DOI: https://doi.org/10.21203/rs.3.rs-362465/v1

License: (9) This work is licensed under a Creative Commons Attribution 4.0 International License. Read Full License 


\section{Abstract}

Herein, a biocompatible and nontoxicity novel type of hydrophobic and hydrophilic co-delivery systems based on co-polymer chitosan-graft-PMMA (ch-g-PMMA) modified Mesoporous silica nanoparticles (MSNPs) for cancer therapy was prepared. The pores of MSNPs were loaded with curcumin (CUR) and doxorubicin (DOX) with co-polymer ch-g-PMMA were gated the pores of MSNPs to prevent the release of drugs. These synthesized ch-g-PMMA/MSNPs dual drug-loaded are effectively allowed for co-delivery of drug combinations with improved efficacy. The dual drug loaded MSNPS were characterized by X-ray diffraction (XRD), Fourier transform infrared spectroscopy (FTIR), UV-Visible spectroscopy (UV-Vis), Transmission electron microscope (TEM) and Brunauer-Emmett-Teller (BET) analysis. The TEM and XRD results proved the successful loading of drugs into the pores of hexagonal structure MSNPs with size $180 \mathrm{~nm}$, CUR and DOX were released from the MSNPs only in acid -triggered manner. The cytotoxicity studied were carried out for ch-g-PMMA/MSNPs dual drug-loaded against adenocarcinoma gastric cell line (AGS) shows that MSNPs was highly biocompatible and well suitable for drug carrier.

\section{Highlights}

- The nanocarrier mesoporous silica is nontoxic to biological system.

- The synthesized carrier can be used to load the twin drugs.

- The selective drug release in acidic condition is helpful to chemotherapeutic agents.

- The synthesized biocomposite showed enhanced anti-cancer activity.

\section{Introduction}

Surface-functionalized MSNPs having excellent drug-delivering properties due to its high loading capacity and porous system, sensitive stimulus-responsive, zero-premature drug release, and controlled drug release properties. These properties make MSNPs interesting and it's used in wide applications in biomedical including bioimaging for diagnostics, [1] biosensing, [2] bio catalysis, [3] bone repair, [4] Scaffold engineering, and drug delivery [5, 6]. MSNPs have first been proposed around 2001 as nanocarriers for transporting therapeutics [7]. In this work, the most important functionalities have triggered the release of the cargo through specially designed gating concepts. In previous articles, the Pore gating systems can consist of nanoparticles such as gold, superparamagnetic iron oxide, and protein, which block the pore entrances for efficient sealing of the interior environment. [8,9]. Premature cargo release will occur in MSNPs to prevent this polymer, oligonucleotides and lipid bilayer were used as gating [10-11].

Nowadays currently available commercial drugs are poorly soluble, limited stability, rapid metabolism, excretion, side effects, and particularly there is a lack of selective target in specific cell types [12-13]. To solve these problems multifunctional MSNPs intended for drug delivery applications because of this highly porous. MSNPs coated with different organic shells will improve the biocompatibility and reach the Loading [MathJax]/jax/output/CommonHTML/jax.js iich will be effective for cancer therapeutics. MSNPs surface 
functionalization is significant for colloidal and chemical solidity as well as for interactions with drugs. Chemical modification of MSNPs with appropriate functional groups offers different binding sites, and an important quantity of a drug can be loaded on the particle surface atmosphere [14-15]. In surfacemodified MSNPs the drugs can be either loaded by incorporation into the matrix or by physical adsorption.

Current research aims to progress functionalized MSNPs for hydrophobic and hydrophilic drug loading for delivery applications. CUR(1,7-bis(4-hydroxy-3-methoxyphenyl)-1,6-heptadiene-3,5-dione) is an important bioactive ingredient, hydrophobic polyphenolic compound and has high potential anti-cancer properties and high-efficiency drug, which is harmless even at high doses but it has few disadvantages like limited aqueous solubility, poor oral bioavailability and multidrug resistance [16-17]. On the other hand, DOX is the best chemotherapy drug, with a vast advantage of anti-cancer and high efficacy, which is hydrophilic in nature. DOX has the following limitations like fast metabolism, low bioavailability, and meagre selectivity for tumor cells and hence it is considered as a model drug for targeting tumors [18]. Here MSNPs pores are gated with the polymer chitosan grafted poly (methyl methacrylate) (PMMA) to prevent premature leakage of drugs while entering the cancer cells. Chitosan and PMMA are biodegradable polymers. Chitosan is prepared from chitin by deacetylation. Chitin is an aminopolysaccharide material with non-toxicity, biodegradability, and compatibility [19-20]. Chitosan has amino and a hydroxyl group, these functional groups provide flexibility for structural modifications. Even though chitosan is poorly soluble in water, but $-\mathrm{OH}$ and $-\mathrm{NH}_{2}$ presence on the chitosan it could be modified chemically. There are only a few works are there for chemically modified chitosan, here we have incorporated chitosan with PMMA has been used as the biocompatible for orthopaedic implant material for over 20 years the world and it is a non-toxic polymer for biomedical applications. PMMA polymer was used as delivery systems of antibiotics in bones and antibiotic-impregnated for musculoskeletal infections since 1970 [21]. Healey et al., 2003 reported that doxorubicin with PMMA for treating bone cancer and delivering doxorubicin [22]. In this work, we have proven the safety of Chitosan and PMMA for the controlled-release of CUR and DOX. Chitosan-graft-PMMA was prepared by surface graft polymerization based on initiating persulfate compounds present in the polymer. This ch-g-PMMA will be a gatekeeper on MSNPs during the delivery of drugs.

We design specific targeting delivery systems for gastric cancer cells by both hydrophobic and hydrophilic drugs. MSNPs pores were loaded with drugs and gated with ch-g-PMMA, which is made up of the combinations of non-toxicity, biocompatibility, pH-development, and time-delayed release mechanisms. These ch-g-PMMA gated MSNPs will be hope for future treatment of gastric cancer with high efficacy and safety. Thus, we have successfully demonstrated here the functionalized MSNPs acts as the safe carrier for both hydrophilic and hydrophobic drugs with responsive drug release properties.

\section{Materials And Methods}

Tetraethyl orthosilicate (TEOS), ethanol (99.9\%), cetyltrimethylammonium bromide (CTAB), Pluronic F127, Loading [MathJax]/jax/output/CommonHTML/jax.js sodium dihydrogen phosphate dihydrate and potassium 
dihydrogen phosphates were purchased from Merck. DOX was purchased from Sigma Aldrich. Chitosan (CS, deacetylation degree of $90 \%$ ) was purchased from Yuhuan Factory, China. Ammonium persulfate and Methyl methacrylate (MMA) of analytical grade with a purity of $98 \%$ were used as the initiators. All the chemicals used were of analytical grade and used without any further purification. Antibiotics for cell culture (penicillin at 10,000 units $\mathrm{mL}^{-1}$ and streptomycin at $10 \mathrm{~g} \mathrm{~L}^{-1}$ ) were purchased from Sigma Aldrich. AGS human gastric cancer cell lines derived from human stomach adenocarcinoma were procured from the National Centre for Cell Science (NCSS), India. DMEM-F12 Ham, Fetal Bovine Serum (FBS), and other growth supplements were purchased from Himedia Chemicals, India. Reagent grade 3(4,5-dimethylthiazol-2-yl) - 2, 5-diphenyl tetra zolium bromide (MTT) was obtained from Calbiochem. Hoechst 33342 and propidium iodide (PI) stains were purchased from Invitrogen.

\subsection{Experiment}

\subsubsection{Preparation of MCM-41-Type Mesoporous silica nanoparticles}

MSNPs were synthesized by the hydrothermal method as per previous reports with slight modification $[23,24]$. The mixture of CTAB $(2.69 \mathrm{~g})$ to the double distilled (DD) water allows dissolving completely by stirring. Pluronic F127 (2 g) to the above solution allows the solution to stir for $2 \mathrm{~h}$. Then added dropwise TEOS (3.5 g) and continuous stir for 30 mins. The white gel solution will be formed by stirring at room temperature. After 30 mins add ammonium hydroxide $(14.7 \mathrm{~mL})$ solution dropwise and continue stirring for $4 \mathrm{~h}$. Transfer the solution into Teflon lined autoclave bottle and heat it at $120^{\circ} \mathrm{C}$ for $8 \mathrm{~h}$. Lately, we have obtained thick white gel. Allow it to rest at room temperature and annealed at $80^{\circ} \mathrm{C}$ for $14 \mathrm{~h}$. Finally, place the white powder in the furnace for $5 \mathrm{~h}$ at $550^{\circ} \mathrm{C}$ remove the excess of polymer and $\mathrm{CTAB}$, and the final product MSNPs with MCM-41 type is formed.

\subsubsection{Preparation of ch-g-PMMA gated MSNPs with dual drug-loaded nanoparticles.}

$200 \mathrm{mg}$ of MSNPs were dispersed in the double distilled water $10 \mathrm{~mL}$ under sonication for $10 \mathrm{~min}$. CUR and DOX were loaded on MSNPs by amino functionalization through a reaction with (3-aminopropyl triethoxy silane) APTES. CUR was dispersed in $1 \mathrm{~mL}$ of ethanol $(1 \mathrm{mg})$ and $500 \mu \mathrm{L}$ of water-soluble bicin solution (1 mg) were taken and both solutions were added in $10 \mathrm{~mL}$ of water dispersed MSNPs (200 mg) were mixed and stirred for $24 \mathrm{~h}$. Allow it to settle down completely and store in ice-cold condition for $10 \mathrm{~h}$, later filter the solution dry it at room temperature. Dispersed the filtrate MSNPs powder in DD water (25 $\mathrm{mL}$ ). For grafting the polymers take the desired quantity of chitosan and mix with the acetic acid aqueous solution in a three-necked flask, ammonium persulfate $(1 \% \mathrm{wt}, 2.5 \mathrm{~mL})$ was added into the chitosan mixer and make the solution to stir for 30 mins which shown in Fig. 1. After that take the MMA to make completely dissolve in dichloromethane and pour in dropwise to the MSNPs chitosan mixer for graft copolymerization reaction. The pores of MSNPs were completely gated by Ch-g-PMMA after $5 \mathrm{~h}$ of

Loading [MathJax]/jax/output/CommonHTML/jax.js ution was centrifuge at 10000 rpm for 10 mins. The 
precipitate was collected as a drug-loaded sample and the supernatant contains unloaded drug molecules.

\subsection{In-vitro drug loading and encapsulation efficiency.}

To study the maximum drug encapsulation and drug loading efficiency of dual drug loaded MSNPs, two parameters were the optimized amount of nanoparticles and concentration of a drug. Drug releasing solution was collected during loading in an equal interval of time $(1 \mathrm{~h})$ for $24 \mathrm{~h}$. After $24 \mathrm{~h}$ of reaction, complete nanoparticles were separated remaining drugs present solution was extracted with $3 \mathrm{~mL}$ of ethanol and water mixture (1:4), and UV absorbance of the solution was measured [25]. Drug loading and encapsulation efficiency were calculated using equations 1 and 2 respectively.

$$
D L P=\frac{m_{d}}{m_{N P}} \times 100
$$

1

$$
D L E=\frac{m_{d}}{m_{d, s y n}} \times 100
$$

2

Where LP and LE are loading percentage and loading efficiency, md is the mass of drug-loaded into the carrier, $\mathrm{m}_{\mathrm{NP}}$ is the total mass of the drug-loaded nanoparticles (NPs) and $\mathrm{m}_{\mathrm{d} \text {, syn }}$ is the mass of drug used in synthesis.

\subsection{In Vitro Drug Release Kinetics}

The release kinetics study of CUR and DOX from MSNPs concerning time was investigated at room temperature in phosphate buffer $(\mathrm{pH}-5.4,6.8,7.2) .10 \mathrm{mg} \mathrm{mL}^{-1}$ of the synthesized sample was placed in a dialysis membrane tube with a 12000 Da molecular cut off (Himedia, Dialysis membrane-110). This tube was dipped in a beaker containing $50 \mathrm{~mL}$ of PBS buffer. At various time intervals, $2 \mathrm{~mL}$ of the solution was drawn from the release medium and replaced with fresh PBS buffer. The released amount of dual drugs was determined at different time intervals by recording the absorbance of the release medium by a UV-Vis spectrophotometer (Diode-Array spectrophotometer 8453).

\subsection{Cell viability assay}

In vitro cytotoxicity potentials of MSNPs, CUR, DOX and Ch-g-PMMA/MSNPs with dual drugs loaded on adenocarcinoma gastric cell line (AGS) were evaluated by a standard MTT assay. $10^{4}$ AGS cells were seeded in each well of a 96 well plate and incubated for $24 \mathrm{~h}$. After the nanoparticle insult, the media was aspirated carefully and MTT-containing media was added to each well at a level of $0.5 \mathrm{mg} \mathrm{mL}^{-1}$. After 4 $\mathrm{h}$ of incubation in the dark, the media was carefully removed, and the purple formazan was dissolved in 
$100 \mu \mathrm{L}$ of dimethyl sulfoxide (DMSO), further incubation could continue for another $15 \mathrm{~min}$ in the dark. The relative intensity of the dissolved formazan was read at 570 and $630 \mathrm{~nm}$ in a microplate reader.

\subsection{Physical characterization}

The structure and morphology of the resulting particles were characterized by XRD using a $\theta / \theta$ Bruker Xray diffractometer (AXS D8 Advance) using a Cu tube $(\lambda=1.5406 \AA)$ with help of Xpert High Score plus software. The UV-Vis absorption spectra were obtained with an Agilent 8453 diode-array spectrophotometer. FT-IR spectrum were analyzed using instrument $8400 \mathrm{~S}$ Shimadzu at the range of $4500-350 \mathrm{~cm}^{-1}$. An electron-transparent specimen was prepared by placing a drop of sample suspended in ethanol onto a carbon-coated copper grid. TEM was performed with a TF 20: Tecnai G2 200kV TEM (FEI).

\section{Result And Discussion}

The preparation of MSNPs loaded with dual drugs and gated co-polymer Ch-g-PMMA is illustrated in Fig. 2. Both CUR and DOX were loaded into the pores by amine functionalization, the amine groups were affixed on the outer surface of MSNPs $\left(\mathrm{NH}_{2}-\mathrm{SiO}\right)$. Amine creates electrostatic interaction among the cationic drug DOX as well as negatively charged (Si-O) pore walls by this DOX were filled into the pores. CUR was filled by hydrophobic interaction and the $\mathrm{NH}_{2}$ functional groups present on the surface of MSNPs have the CUR to form hydrophobic structures. These hydrophobic interactions between CUR and functional groups present in MSNPs enhance the drug adsorption on the surface. The positively charged amine group plays a vital role in the increased loading capacity. Ch-g-PMMA co-polymerization was prepared by using ammonium persulfate as an initiator. During co-polymerization, the ester group present in the polymer gets hydrolysed to $-\mathrm{COOH}$, and the carboxyl group has an oxygen atom it had a negative charge which easily bind to the positive charge of the amine group of MSNPs and which gets easily protonated, through this ch-g-PMMA copolymer completely gate the pore of MSNPs. The TEM image of MSNPs shows the spherical shape of well-dispersed particles. The average diameter of the MSNPs is about $150 \mathrm{~nm}$ which is shown in Fig. 3. After the dual drugs were loaded and pores were gated with copolymer ch-g-PMMA the size of MSNPs was increased to $180 \mathrm{~nm}$ which is shown in Fig. 3 . These results provide the successful loading of drugs into the pores; dark spots appeared on the particle surface which is clearly seen in the TEM image of Fig. 3. After the complete release of both drugs from the MSNPs TEM image clearly shows the hexagonally packed mesoporous channels.

Figure 4, shows X-ray diffractions (XRD) pattern of synthesized NPs, peaks appeared at $2.2^{\circ}$ which correspond to (100) plane [25] with the type of MCM-41. The synthesized MSNPs have a structure of the hexagonal structure. A significant decrease in the intensity of the diffractions peaks also identified after the loading of drugs (CUR and DOX) shown in Fig. 4. These XRD patterns suggest that drugs were successfully loaded into the MSNPs.

The loading of drugs was firmed by the UV-Vis spectrum shown in Fig. 5. The synthesized NPs were Loading [MathJax]/jax/output/CommonHTML/jax.js 5 a is the bare MSNPs that does not exhibit any characteristic 
peak. From Fig. 5b, the loading of drugs was confirmed by the UV-Visible spectra. The two distinct peaks at 280 and $425 \mathrm{~nm}$ confirms the presence of water dispersed CUR/DOX/MSNPs. From the PL emission, the drug-loaded shows two distinct peaks at the range of 390 and $430 \mathrm{~nm}$ which corresponds to DOX and CUR. This PL emission data give positive results that drugs were loaded into the pores of MSNPs.

The FT-IR spectrums of synthesized nanoparticles are shown in Fig. 6 . and the spectra measured in the range of 3500 to $500 \mathrm{~cm}^{-1}$ the peaks are which is reassemble as previous studies. In Fig. 6a the peak appears at the range of 468 and $972 \mathrm{~cm}^{-1}$ are assigned for Si-O bond stretching vibration and Si-OH groups. The bare MSNPs silanol groups Si-O-H were appeared at $3000 \mathrm{~cm}^{-1}$ and Si-O-Si stretching vibration of $\mathrm{SiO}_{4}$ asymmetric band appeared at $1100 \mathrm{~cm}^{-1}$ [26-27], while the symmetric one is at 800 $\mathrm{cm}^{-1}$. In Fig. $6 \mathrm{~b}$ after loading of drugs, the spectrum shows all characterization peaks of both CUR and DOX. The peak appears at $1632,1592,1510 \mathrm{~cm}^{-1}$ are assigned for $\mathrm{C}-0$ stretching, $\mathrm{C}=0$ vibration for ketone, and phenol groups [28]. The peak appeared at $3500 \mathrm{~cm}^{-1}$ for the $-\mathrm{OH}$ stretching band of phenol hydroxyl groups. Characteristic of doxorubicin the peak appears at $2940 \mathrm{~cm}^{-1}$ is assigned for $\mathrm{C}-\mathrm{H}, 1620$ $\mathrm{cm}^{-1}$ is stretching vibration of $\mathrm{N}-\mathrm{H}, 1400 \mathrm{~cm}^{-1}$ for $\mathrm{C}-\mathrm{C}$ and finally the peak $1070 \mathrm{~cm}^{-1}$ is assigned for $\mathrm{C}-\mathrm{O}$ [29]. In Fig. 6c FT-IR spectrum is Ch-g-PMMA/MSNPs with drug-loaded nanoparticles in this the peak appeared at 1720, $2952 \mathrm{~cm}^{-1}$ were assigned for the carbonyl stretching, symmetrical and asymmetrical stretching of methyl groups present in the polymer. For chitosan the absorption peaks at $1628,1510 \mathrm{~cm}^{-}$

1 are attributed to amide band due to the plane of $\mathrm{N}-\mathrm{H}$ deformation the peak intensity is week. $2585 \mathrm{~cm}^{-1}$ is assigned for S-H but the intensity of the peak is the weak [30]. These FT-IR spectra provide that successful formation of Ch-g-PMMA copolymer on the surface of MSNPs but the characteristic peak of drug CUR and DOX has not appeared. This described the successful synthesis of Ch-g-PMMA/MSNPs with drugs loaded.

\subsection{BET analysis}

The surface modification of the MSNPs and drug-loaded MSNPs was studied by Brunauer-EmmettTeller (BET) analysis. According to $\mathrm{N}_{2}$ adsorption and desorption measurements, BET analysis was shown in Fig. 7. The synthesized MSNPs the pore diameter is about $8.2 \mathrm{~nm}$ and it has a very high surface area of $585.2 \mathrm{~m}^{2} \mathrm{~g}^{-1}$, a pore volume of $3.11 \mathrm{~cm}^{3} \mathrm{~g}^{-1}$ this shows the MSNPs have a high potential to carry both the drugs. After loading drugs, the hysteresis loop becomes very thin along with a reduced BET surface area of $39.8 \mathrm{~m}^{2} \mathrm{~g}^{-1}$ and pore volume of $3.11 \mathrm{~cm}^{3} \mathrm{~g}^{-1}$, the mesopore size of ch-g-PMMA/MSNPs with drugs was decreased to $6.12 \mathrm{~nm}$ due to the pore filling effect. These results suggesting that by physical adsorption of curcumin and doxorubicin may completely block the pores of MSNPs.

\section{2 pH-Responsive Drug release property.}

The drug loading content and entrapment efficacy of synthesized nanoparticles were up to $23 \%$ and $58 \%$ respectively at room temperature. These results indicate that MSNPs possess high drug loading Loading [MathJax]/jax/output/CommonHTML/jax.js -releasing behavior of ch-g-PMMA/MSNPs with drugs was 
studied in three different physiological $\mathrm{pH}(7.2,6.8$, and 5.4$)$ at room temperature is shown in the Fig. 8. The cumulative releases of drugs were occurred only at a pH of 5.4 up to $72 \%$ at 24 hours. At pH 6.8 and 7.2 only 61 and $24 \%$ in 24 hours, when the $\mathrm{pH}$ increased the drug-releasing rate was decreased. In pH 5.4 releasing percentage was high this is due to the electrostatic interaction was very strong between the copolymer and template molecules of drugs (CUR and DOX). The highly protonated functional group like amine present in the drug (DOX) particularly in acidic medium produce high binding energy so that the drug-releasing was high compared to another $\mathrm{pH}$. In $\mathrm{pH} 6.8$ and 7.2, the electrostatic force was very weak, and functional group amine protonation of drugs produce low binding energy so that drug release was very low. Therefore $\mathrm{pH}$-dependent CUR and DOX from Ch-g-PMMA/MSNPs are of excessive interest in therapeutic applications. More importantly, these MSNPs is assessed to be a good carrier of both hydrophobic and hydrophilic drugs.

\subsection{Cell viability assay}

MTT assay was performed to study the cell viability of drug loaded Ch-g-PMMA/MSNPs with seven different concentrations ( $5 \mu \mathrm{g} / \mathrm{ml}, 10 \mu \mathrm{g} / \mathrm{ml}, 25 \mu \mathrm{g} / \mathrm{ml}, 50 \mu \mathrm{g} / \mathrm{ml}, 100 \mu \mathrm{g} / \mathrm{ml}, 150 \mu \mathrm{g} / \mathrm{ml}$ and $200 \mu \mathrm{g} / \mathrm{ml}$ ) at a time interval of $24 \mathrm{~h}$. From the graph Fig. 9 it is obvious, the percentage of cell viability decreases in a dose dependent as well as time dependent manner. The $\mathrm{IC}_{50}$ values were calculated for CUR, DOX and synthesized drug loaded biomaterial and its values were found to be $98.8449 \mu \mathrm{g} / \mathrm{ml}, 90.3549 \mu \mathrm{g} / \mathrm{ml}$ and $52.49 \mathrm{\mu g} / \mathrm{ml}$ respectively. We found that the cells treated with drug loaded biomaterial showed suppressed growth compared with the controls. Subsequently the inhibition of cell proliferation decreases when the cells were exposed with drug loaded Ch-g-PMMA/MSNPs suggesting the prepared biomaterial have the potential to inhibit the development of tumor cell line (AGS) and hence it could be extended to use as anti-tumor drug for in vivo models in future.

The morphological analysis of AGS gastric cancer cell lines was performed in high content screening images in Perkin-Elmer operates the HSC system. After treating with synthesized NPs in cancer cell lines which are shown in Fig. 10. The untreated control cell image Fig. 10a shows normal nuclei. The cells were treated with synthesized nanoparticles shows condensed and fragment nuclei in $24 \mathrm{~h}$ of the incubation period. After treatment with synthesized NPs, cell death occurred by induced apoptosis. Compared to other materials the ch-g-PMMA/MSNPs with dual drug-loaded shows remarkable cell death. These observations further demonstrate the enhanced anticancer activity of the NPs relative to its essential nanomaterials.

\section{Conclusion}

A novel and biocompatible ch-g-PMMA/MSNPs with dual drug-loaded has been successfully prepared. The functional groups present in the MSNPs and polymer have been improved and conjugated with both hydrophobic, hydrophilic drugs. The resulting polymer shells acted being gate to prevent the burst let out of drugs in the physiological pH (6.8 and 7.2) from the MSNPs which serves as the reservoir for both the 
observed in an acidic environment pH 5.4. The in-vitro cytotoxicity shows excellent results and reveals that synthesized nanoparticles are non-toxicity, highly biocompatible, and suitable for drug carriers. Ch-gPMMA/MSNPs with drugs loaded show great prospective as a pH-responsive co-delivery system for cancer treatment.

\section{Declarations}

\section{Funding Statement}

The author(s) received no financial support for the research, authorship, and/or publication of this article.

\section{Conflicts of interest/Competing interests}

The authors declare that there is no conflict of interests regarding the publication of this paper.

\section{Authors' contributions}

Mrs. K.Priyadharsini: Preparation and Characterization of the material, Original draft preparation.

Dr. M.Anbuchezhiyan: Planning, Designing and guidance of overall research.

Dr. K. Sangeetha: Scientific Discussion.

Mr. N. Senguttuvan: Review and Editing.

Dr. Rajendran Sribalan: Testing and analysis (in vitro biological studies).

\section{Availability of data and material}

Spectral details are available

Compliance with ethical Standards

Not Applicable

Code availability

Not applicable.

\section{Consent to participate}

Consent ensures all the authors agree to your terms and conditions.

\section{Consent for publication}

Consent ensures that the Publisher has the Author's permission to publish the relevant Contribution. 


\section{Acknowledgement}

Not applicable for this section

\section{References}

1. Jafari S, Derakhshankhah H, Alaei L, et.al. (2019) Mesoporous silica nanoparticles for therapeutic/diagnostic applications, Biomedicine \& Pharmacotherapy. 109:1100-1111.

2. Slowing II, Trewyn, Giri B G, et.al, (2007) Mesoporous Silica Nanoparticles for Drug Delivery and Biosensing Applications, Adv.Func 17:1225-1236

3. Kalantari, M., Yu, M., Yang, Y. et al. (2017) Tailoring mesoporous-silica nanoparticles for robust immobilization of lipase and biocatalysis. Nano Res. 10, 605-617.

4. Liu X H, Xue S, Ma J Z,Zhongguo gu Shang. (2020) Mesoporous silica nanoparticles for bone tissue engineering China Journal of Orthopaedics and Traumatology. 33:784-787.

5. Manzano M, Vallet-Regí M, (2020) Mesoporous Silica Nanoparticles for Drug Delivery, Smart and Responsive Micro- and Nanostructured Materials, 30:

6. Carvalho G C, Sábio RM, Ribeiro T D C, et al. (2020) Highlights in Mesoporous Silica Nanoparticles as a Multifunctional Controlled Drug Delivery Nanoplatform for Infectious Diseases Treatment. Pharm Res., 37:

7. Bharti C, Nagaich U, Pal A K, Gulati N. (2015) Mesoporous silica nanoparticles in target drug delivery system: A review. Int J Pharm Investig. 5:124-133.

8. Giri S, Trewyn B G, Stellmaker M P, et.al, Chem., Int. Ed. 2005; 44: 5038-5044.

9. Schlossbauer A, Kecht J, Bein T. Angew Chem., Int. Ed. 2009;48:3092-3095.

10. Liu R, Liao P H, Liu J K, Feng P Y, (2011)Responsive polymer coated mesoporous silica as a pHsensitive nanocarrier for controlled release Langmuir 27:3095-3099.

11. Cauda V, Argyo C, Bein T. (2010) Impact of different PEGylation patterns on the long-term bio-stability of colloidal mesoporous silica nanoparticles J Mater. Chem. 20:8693-8699.

12. Patra J K, Das G, Fraceto L F, et al. (2018) Nano based drug delivery systems: recent developments and future prospects. J Nanobiotechnology. 16:

13. Navya P N, Kaphle A, Srinivas S P. et al. (2019) Current trends and challenges in cancer management and therapy using designer nanomaterials. Nano Convergence. 6: 23 
14. Fortuni B, Inose T, Ricci M. et al. (2019) Polymeric Engineering of Nanoparticles for Highly Efficient Multifunctional Drug Delivery Systems. Sci Rep 9:

15. Narayan R, Usha Y. Nayak, Ashok M. Raichur, Sanjay Garg, (2018) Mesoporous Silica Nanoparticles: A Comprehensive Review on Synthesis and Recent Advances, Pharmaceutics. 10:

16. Dhivya R, Ranjani J, Rajendhran J, Mayandi J, Annaraj J, (2018) Enhancing the anti-gastric cancer activity of curcumin with biocompatible and $\mathrm{pH}$ sensitive PMMA-AA/ZnO nanoparticles, Materials Science \& Engineering C. 82:182-189.

17. Dhivya R, Ranjani J, Bowen P K, Rajendhran J, Mayandi J, Annaraj J, Biocompatible curcumin loaded PMMA-PEG/ZnO nanocomposite induce apoptosis and cytotoxicity in human gastric cancer cells, Materials Science and Engineering C. 2017;80: 59-68.

18. Shen J, He Q, Gao Y, Shi J, Li Y, Mesoporous silica nanoparticles loading doxorubicin reverse multidrug resistance: performance and mechanism, Nanoscale, 2011;3: 4314-4322.

19. Grenha A. et al. Chitosan nanoparticles are compatible with respiratory epithelial cells in vitro. Eur J Pharm Sci., 2007;3:73-84.

20. Ghaffari A. et al. Preparation and characterization of free mixed-film of pectin/chitosan/Eudragit RS intended for sigmoidal drug delivery. Eu J pharm Biopharm., 2007;67:175-186.

21. Ridhima J, and Indrajit R, Surface modified PMMA nanoparticles with tunable drug release and cellular uptake. RSC Adv, 2014;4:44472-44479

22. Healey J H, Shannon F, et al. PMMA to stabilize bone and (2003) Deliver antineoplastic and antiresorptive agents. Clin Orthop Relat. Res. 415:S263-S275.

23. Yu Q, Hui J, Wang P, Xu B, Zhuang J and Wang X, (2012) Hydrothermal synthesis of mesoporous silica spheres: effect of the cooling process, Nanoscale, 4:7114-7120.

24. Wibowo F R, Saputra O A, Witri W. et al. (2020) pH-Triggered Drug Release Controlled by Poly(Styrene Sulfonate) Growth Hollow Mesoporous Silica Nanoparticles, ACS Omega 5:4261-4269.

25. Szegedi A, Popova M, Goshev I, Miha J, (2011) Effect of amine functionalization of spherical MCM41 and SBA-15 on controlled drug release, Journal of Solid State Chemistry. 184:1201-1207.

26. Amama PB, Lim S, Ciuparu D, et al. (2005) Hydrothermal synthesis of MCM-41 using different ratios of colloidal and soluble silica. Microporous Mesoporous Mater. 81:191-200.

27. Xie Y, Tang A and Yang H, (2015) Synthesis of Nanoporous Materials Al-MCM-41 from Natural Halloysite, Nano, 10: 
28. Nihal S. Elbialya,b, Samia Faisal Aboushoushaha, Balsam Fahad Sofia, Abdulwahab Noorwalid, (2020) Multifunctional curcumin-loaded mesoporous silica nanoparticles for cancer chemoprevention and therapy, Micropor. and Mesopor. Mater. 291:

29. Unsoy G, Khodadust R, Yalcin S, et al. (2014) Synthesis of Doxorubicin loaded magnetic chitosan nanoparticles for $\mathrm{pH}$ responsive targeted drug delivery, European Journal of Pharmaceutical Sciences.62:243-250.

30. Zheng X F, Qi Lian Q, et al. Surface (2016) Molecularly Imprinted Polymer of Chitosan Grafted Poly(methyl methacrylate) for 5-Fluorouracil and Controlled Release, Scientific Reports. 6:21409.

\section{Figures}

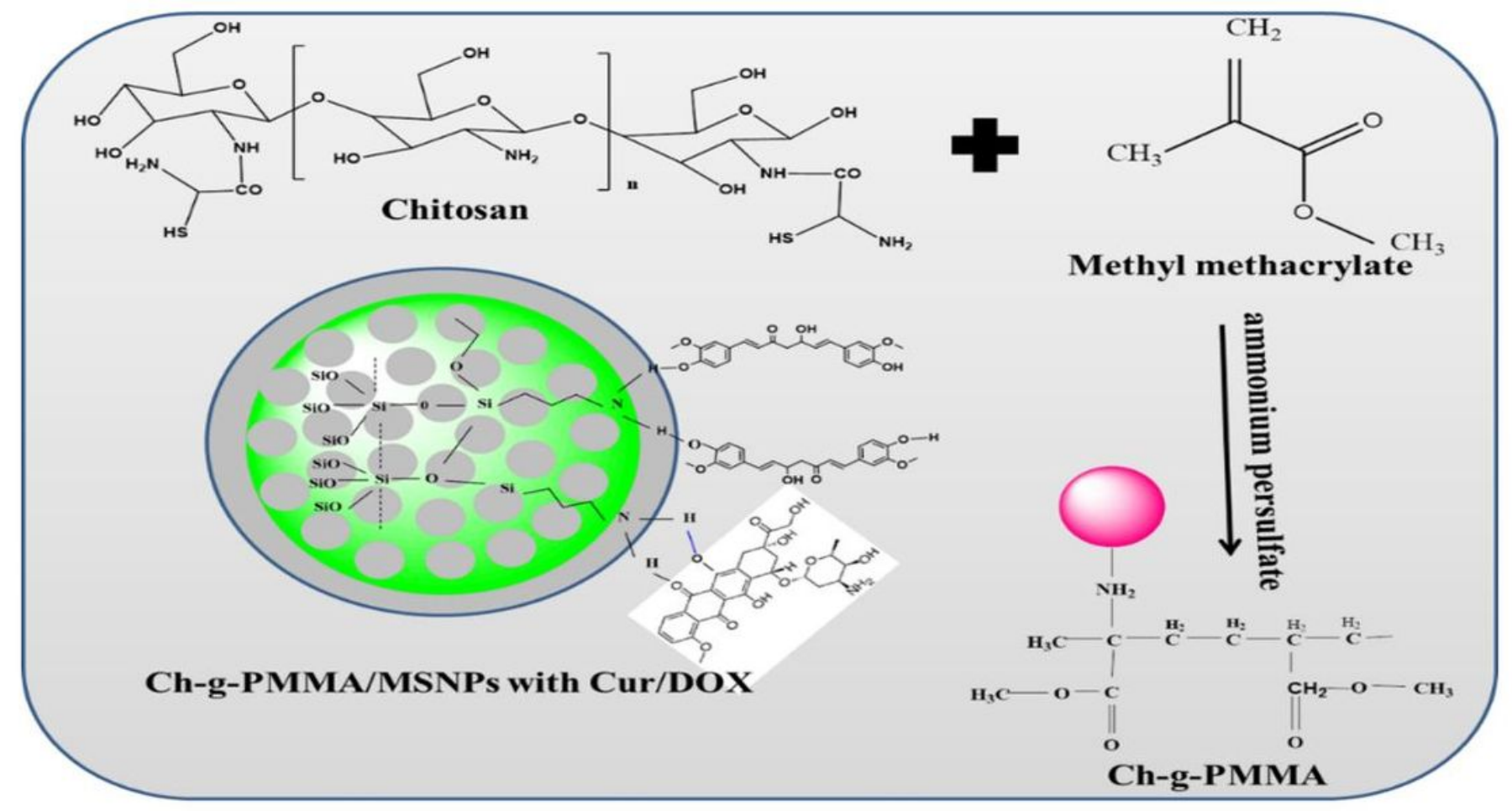

Figure 1

Scheme of Ch-g-PMMA polymer synthesis 


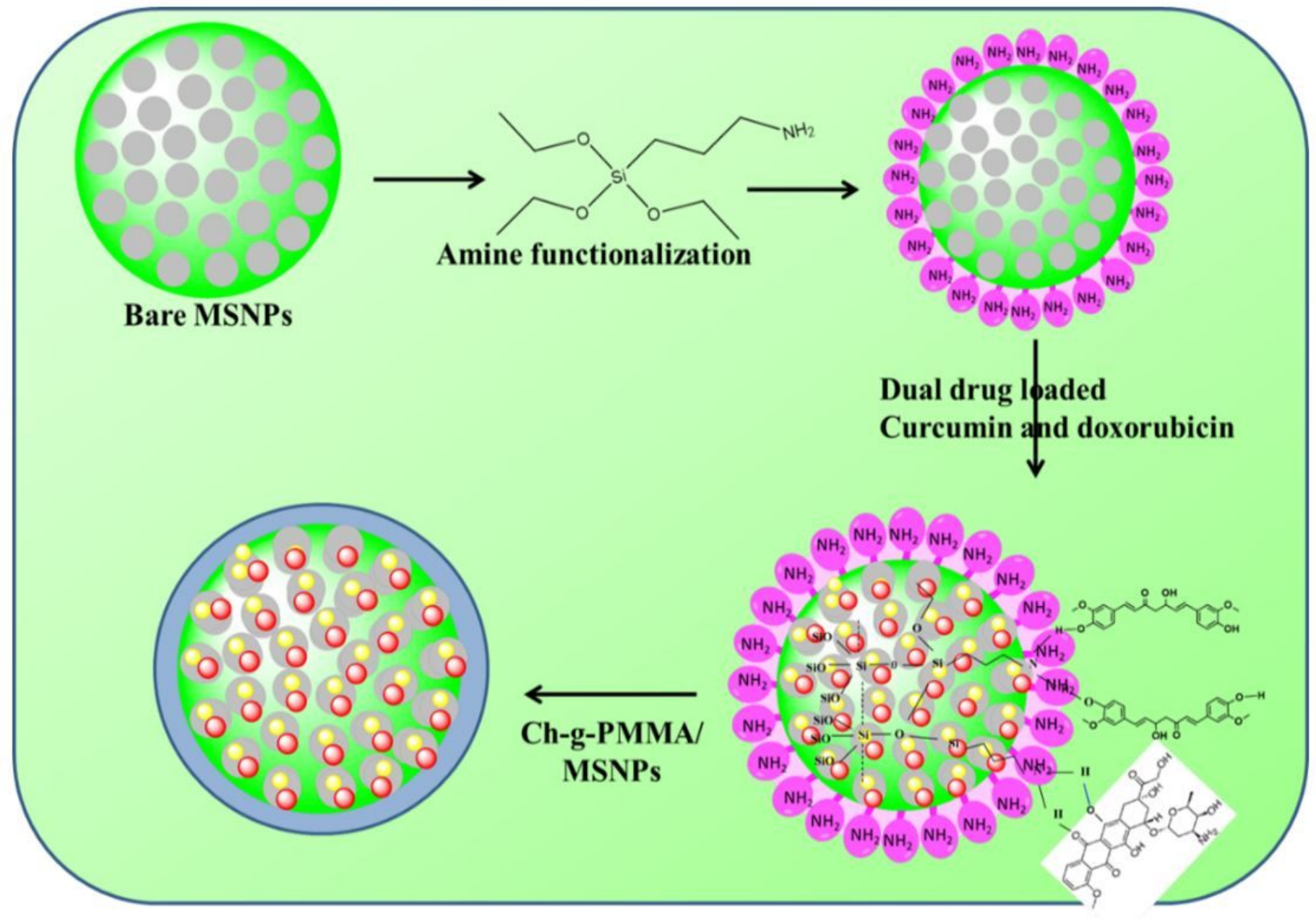

Figure 2

Scheme of Ch-g-PMMA/MSNPs with dual drug-loaded
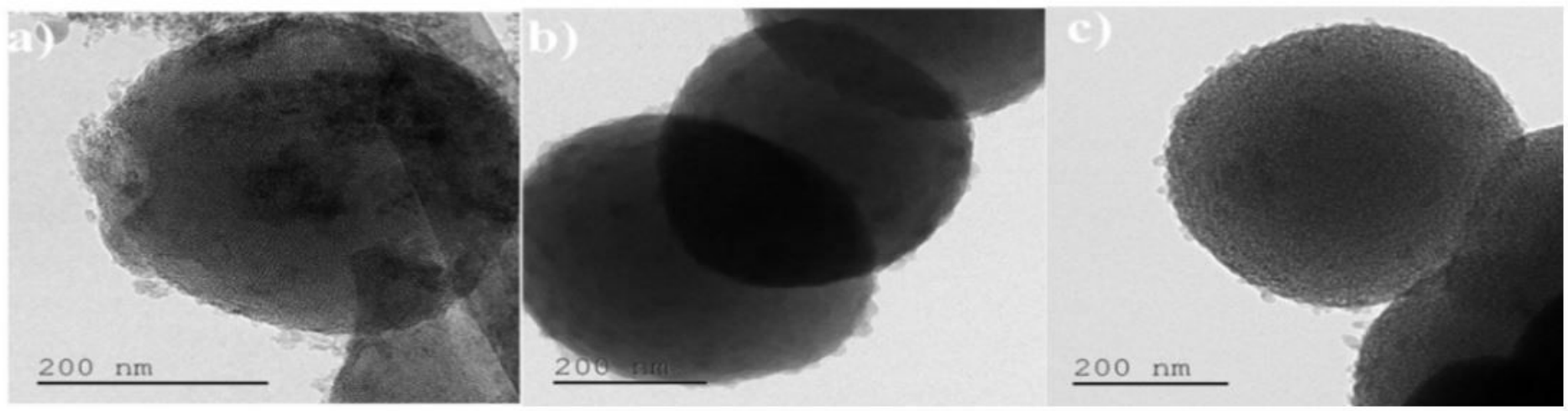

Figure 3

a) MSNPs b) Ch-g-PMMA/MSNPs with dual drugs and c) TEM micrographs of the sample found after complete releasing of drugs 


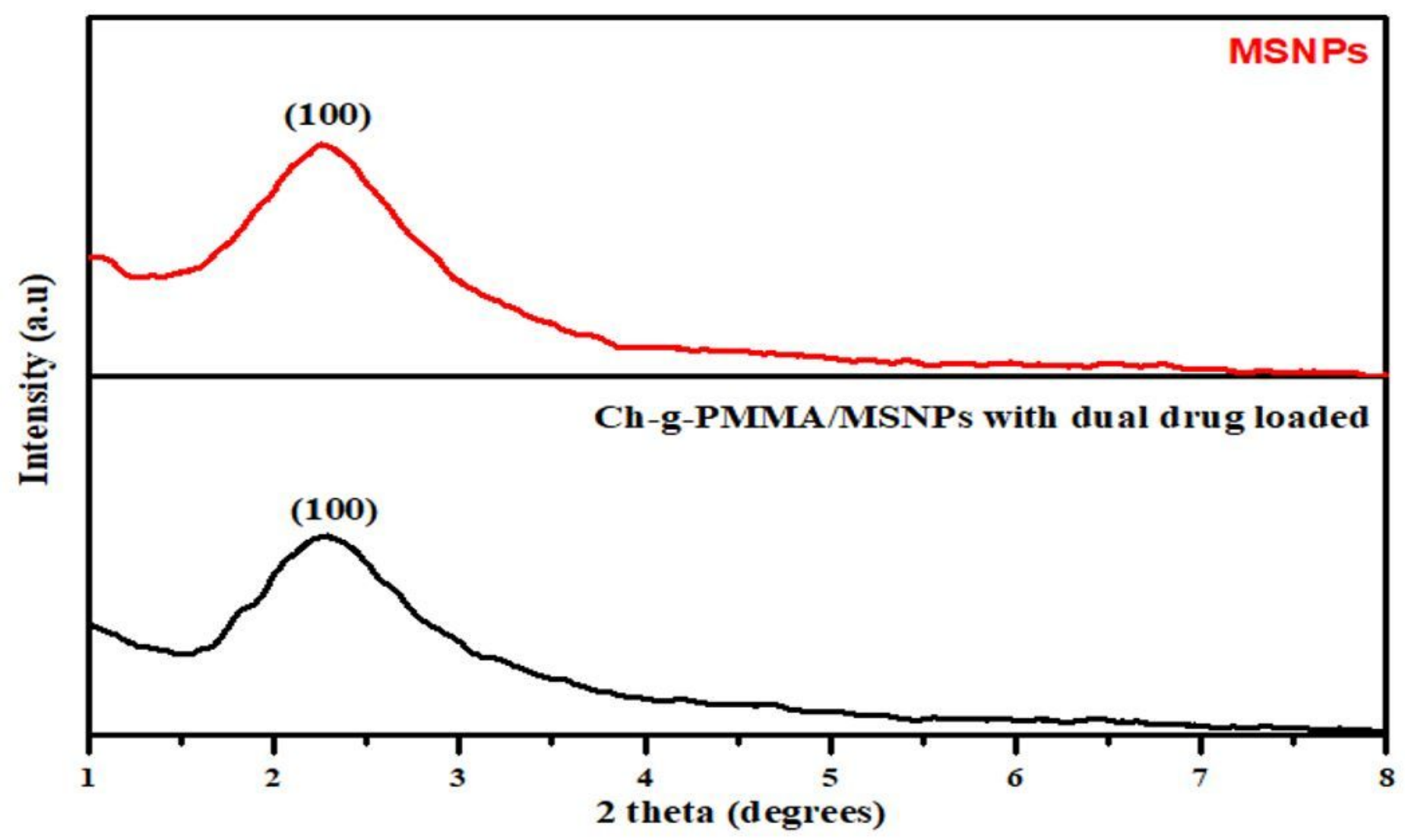

Figure 4

XRD pattern of synthesized NPs 

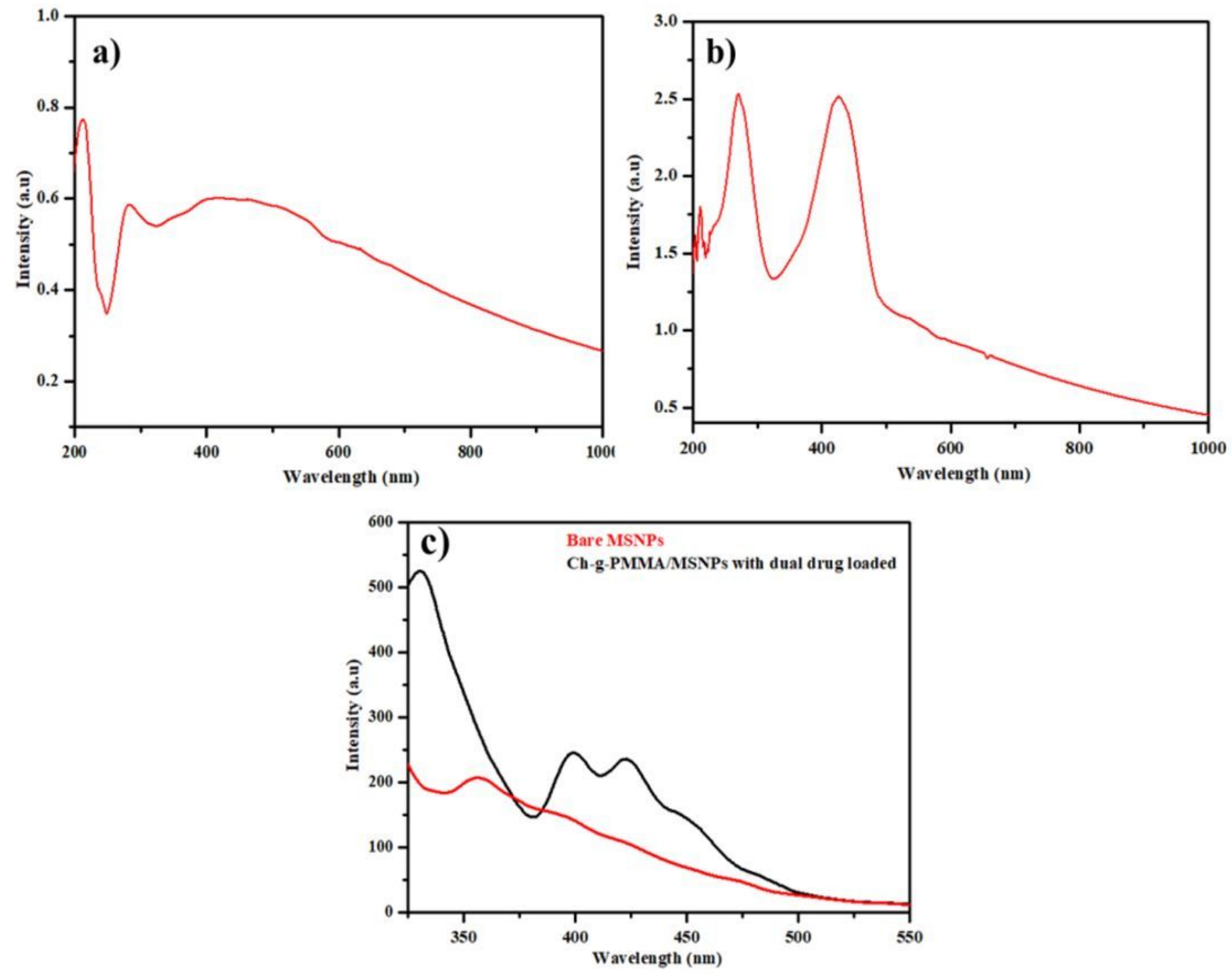

Figure 5

UV-Vis spectrum of a) Bare MSNPs, b) Ch-g-PMMA/MSNPs with drugs loaded and PL emission of synthesized NPs 

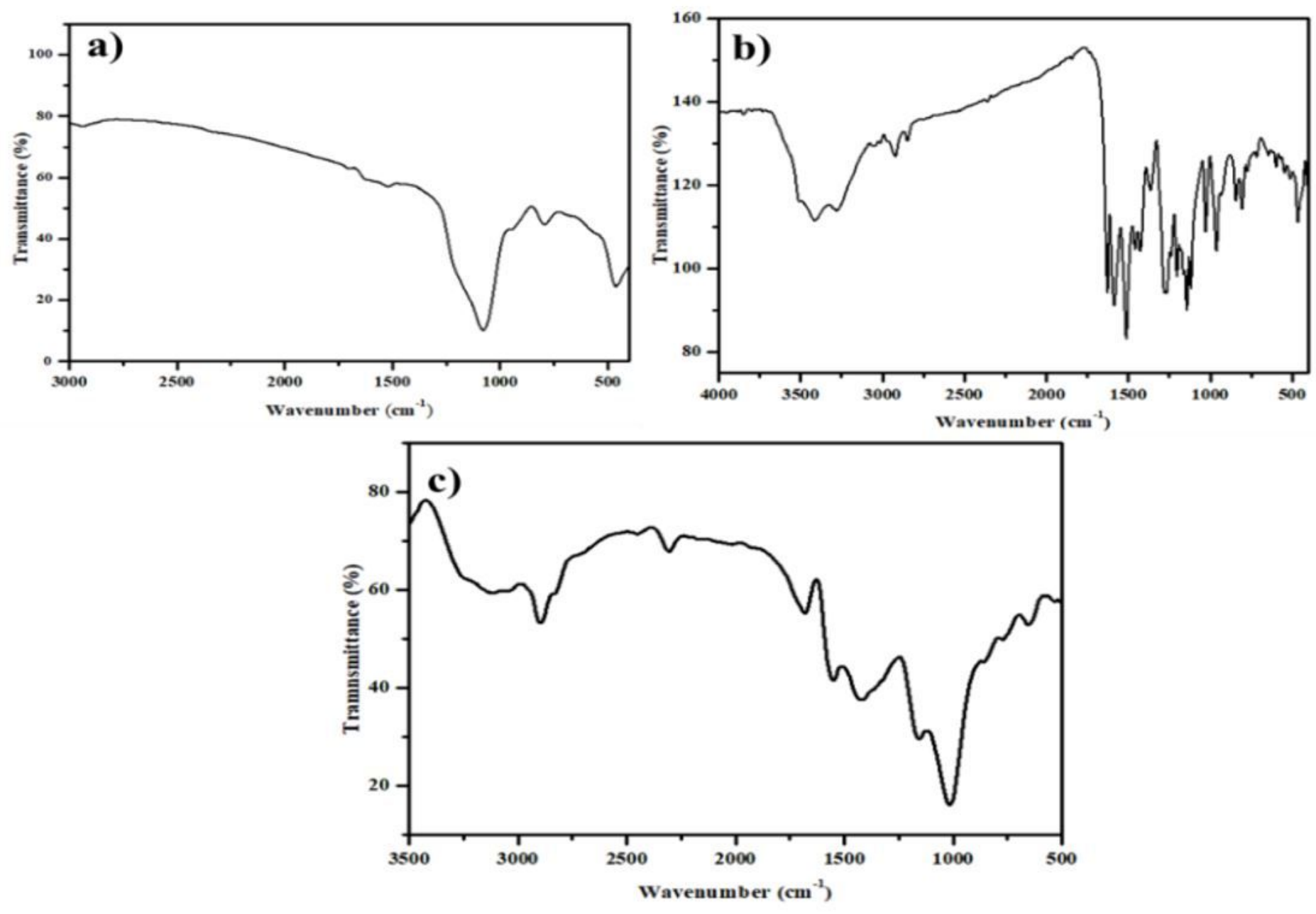

Figure 6

FT-IR spectra of a) Bare MSNPs, b) CUR/DOX/MSNPs, and Ch-g-PMMA/MSNPs loaded with drugs 


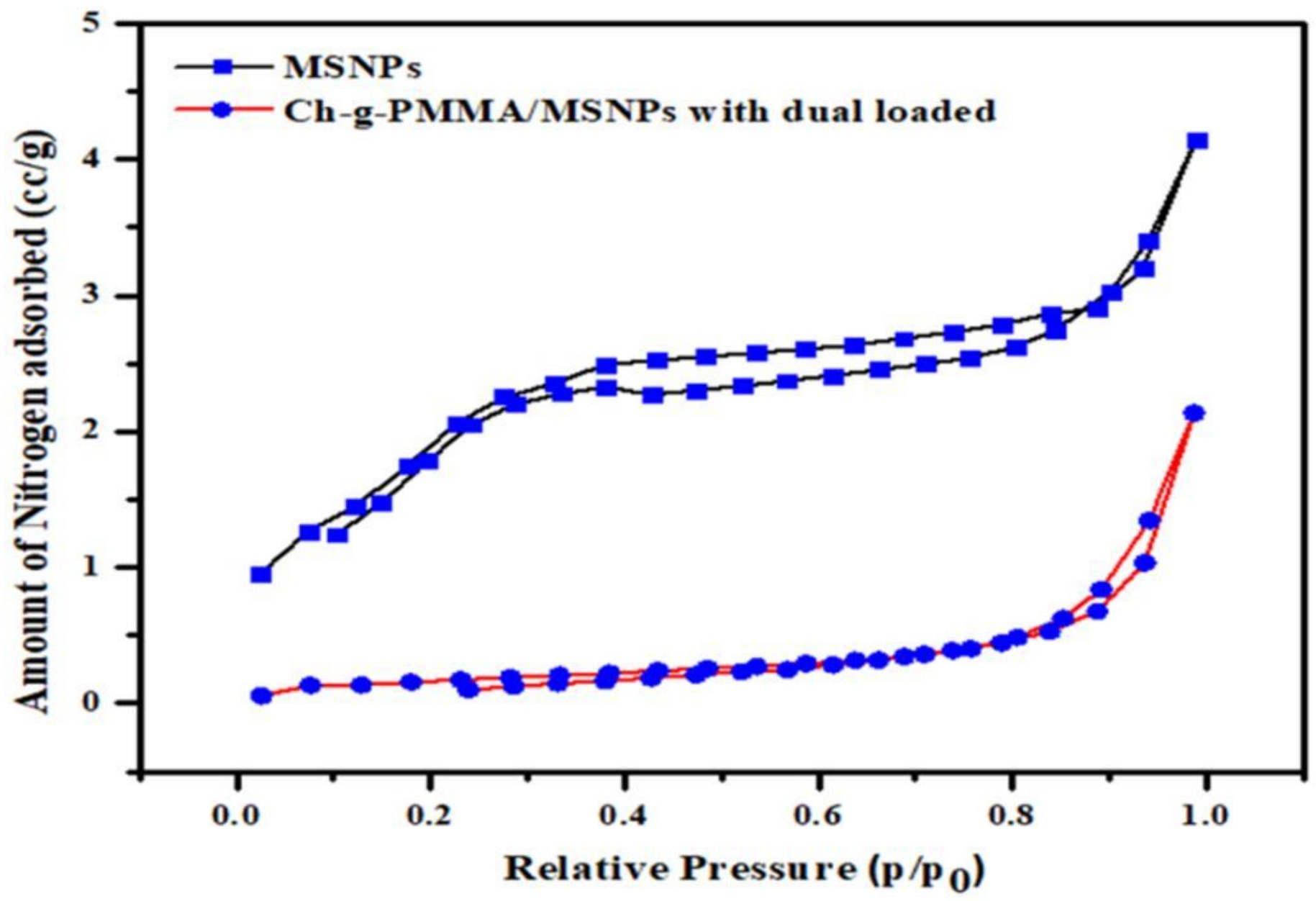

Figure 7

BET analysis of synthesized NPs 


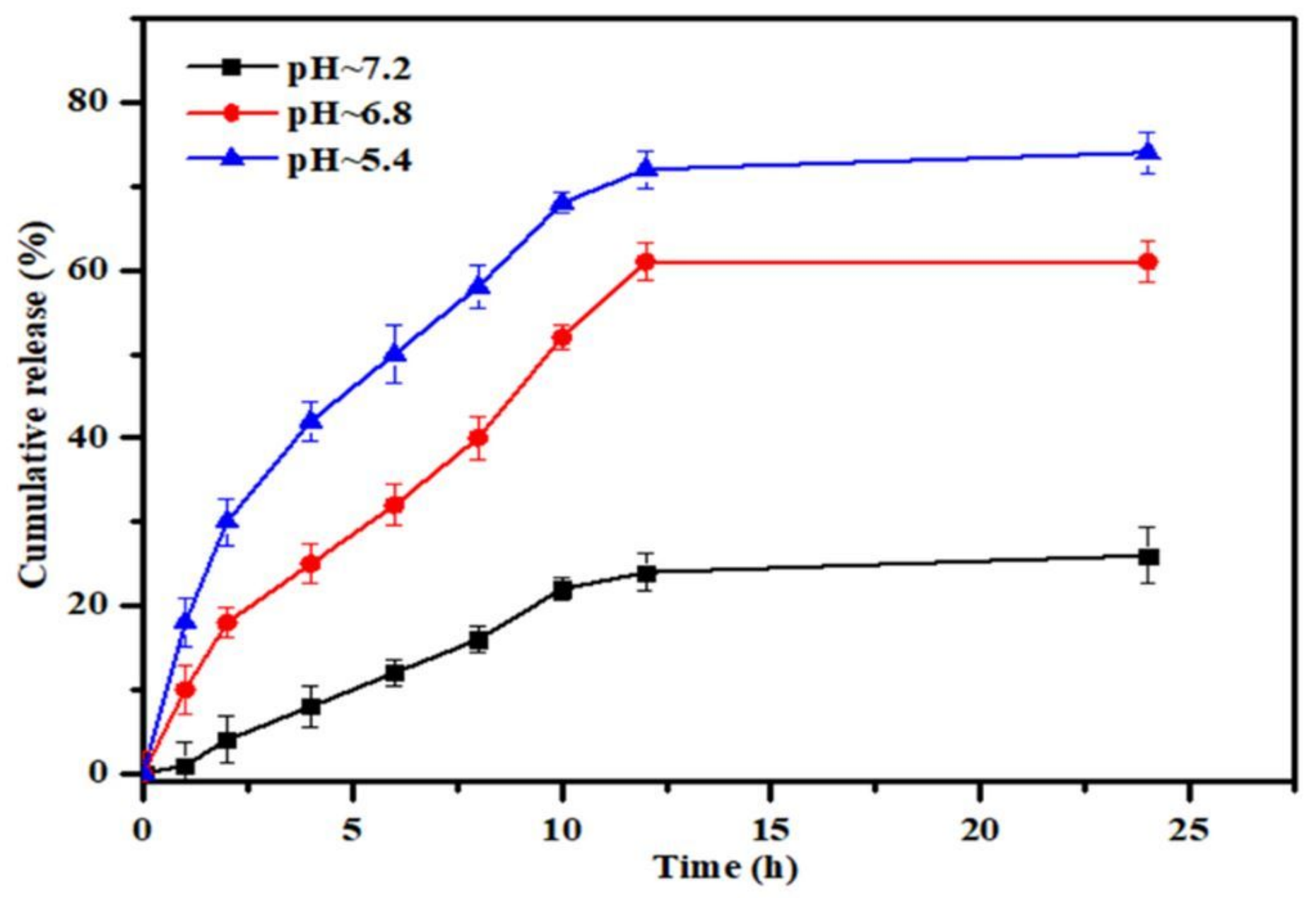

Figure 8

$\mathrm{pH}$-dependent in vitro release of drugs forms ch-g-PMMA/MSNPs. 


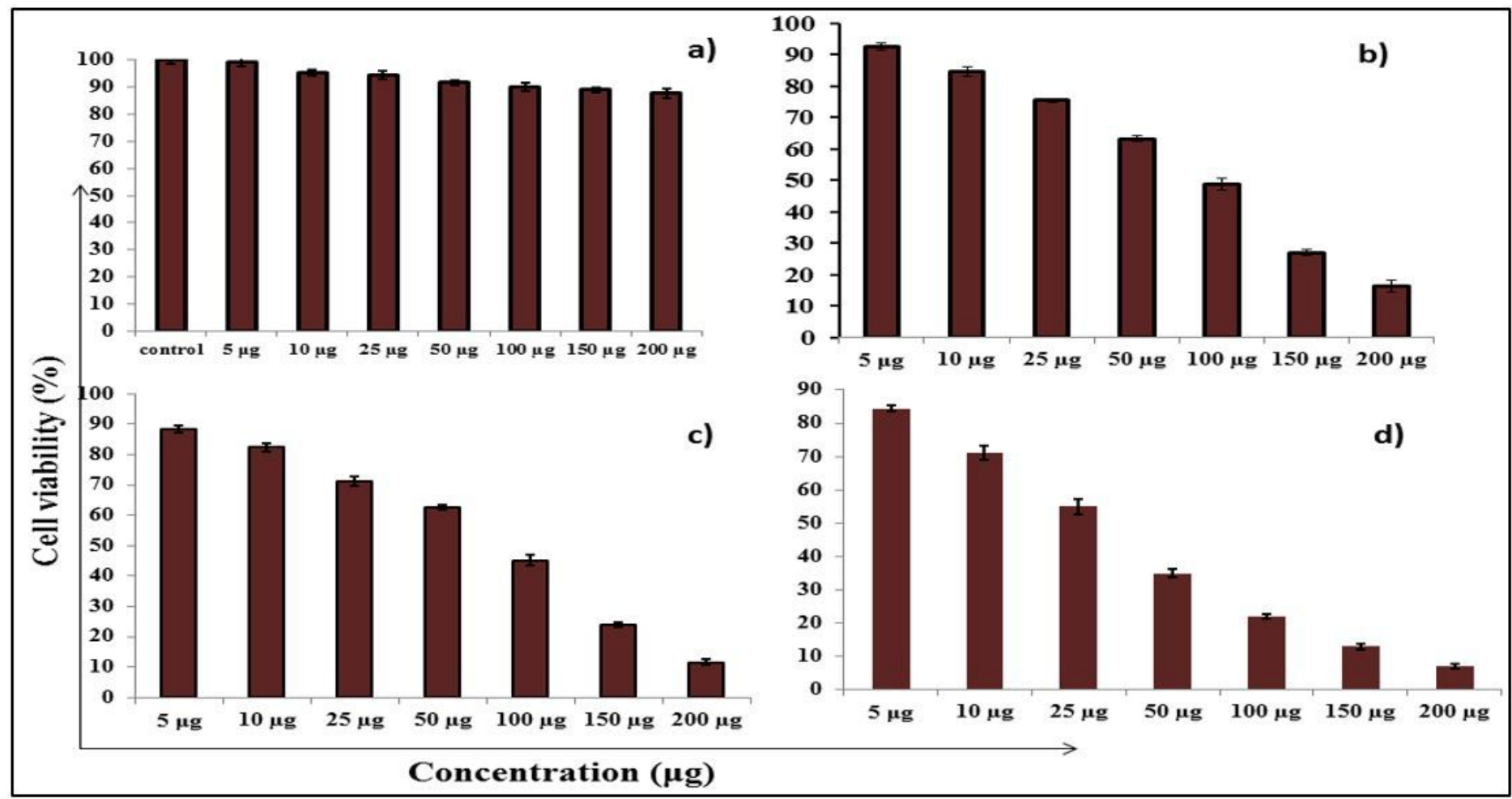

Figure 9

Cell viability assay of a) MSNPs, b) CUR c) DOX and d) ch-g-PMMA/MSNPs with dual drug-loaded
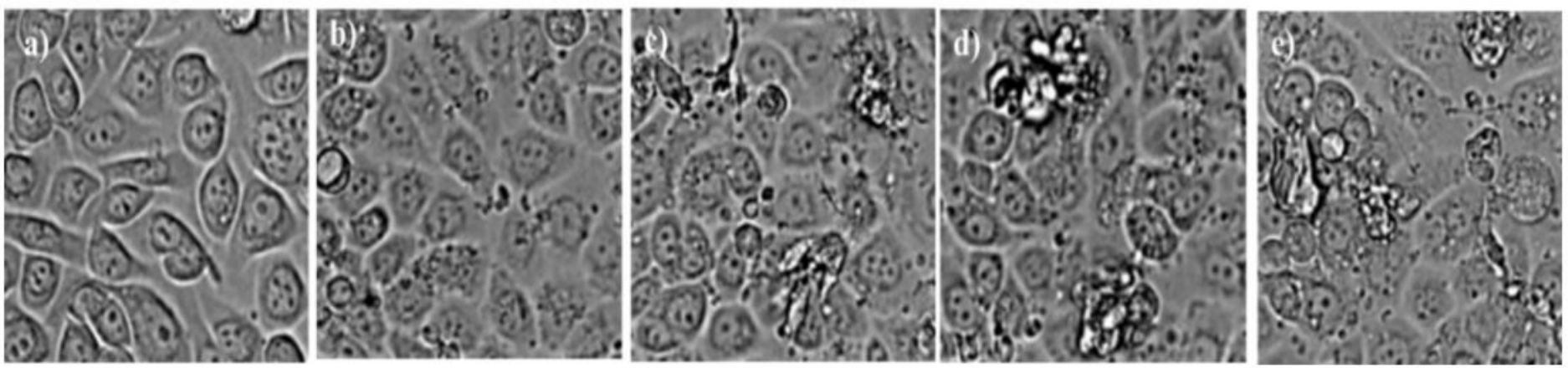

Figure 10

Morphological analysis of AGS gastric cell lines in presence of a) Control, b) MSNPS, c) CUR d) DOX and e) ch-g-PMMA/MSNPs with dual drug-loaded

\section{Supplementary Files}

This is a list of supplementary files associated with this preprint. Click to download.

- GraphicalAbstract.docx 